"This document is the Accepted Manuscript version of a Published Work that appeared in final form in ChemSoc.Rev, copyright (C) The Royal Society of Chemistry 2017 after peer review and technical editing by the publisher. To access the final edited and published work see:

http://pubs.rsc.org/en/content/articlelanding/2017/cs/c7cs00248c\#!divAbstract

\title{
How to Make an Efficient and Robust Molecular Catalyst for Water Oxidation
}

Pablo Garrido-Barros, ${ }^{a, b}$ Carolina Gimbert-Suriñach, ${ }^{a}$ Roc Matheu,,${ }^{a, b}$ Xavier Sala ${ }^{c}$ and Antoni Llobet $^{\mathrm{a}, \mathrm{c} *}$

${ }^{a}$ Institute of Chemical Research of Catalonia (ICIQ), Avinguda Països Catalans 16, 43007 Tarragona, Spain.

b Departament de Química Física i Inorgànica, Universitat Rovira i Virgili, Marcel·lí Domingo s/n, 43007 Tarragona, Spain.

c Departament de Química, Universitat Autònoma de Barcelona, Cerdanyola del Vallès, 08193 Barcelona, Spain.

\section{KEYWORDS}

Transition metal complexes

Water oxidation catalysis

Water splitting,

New energy conversion schemes

Degradation pathways 


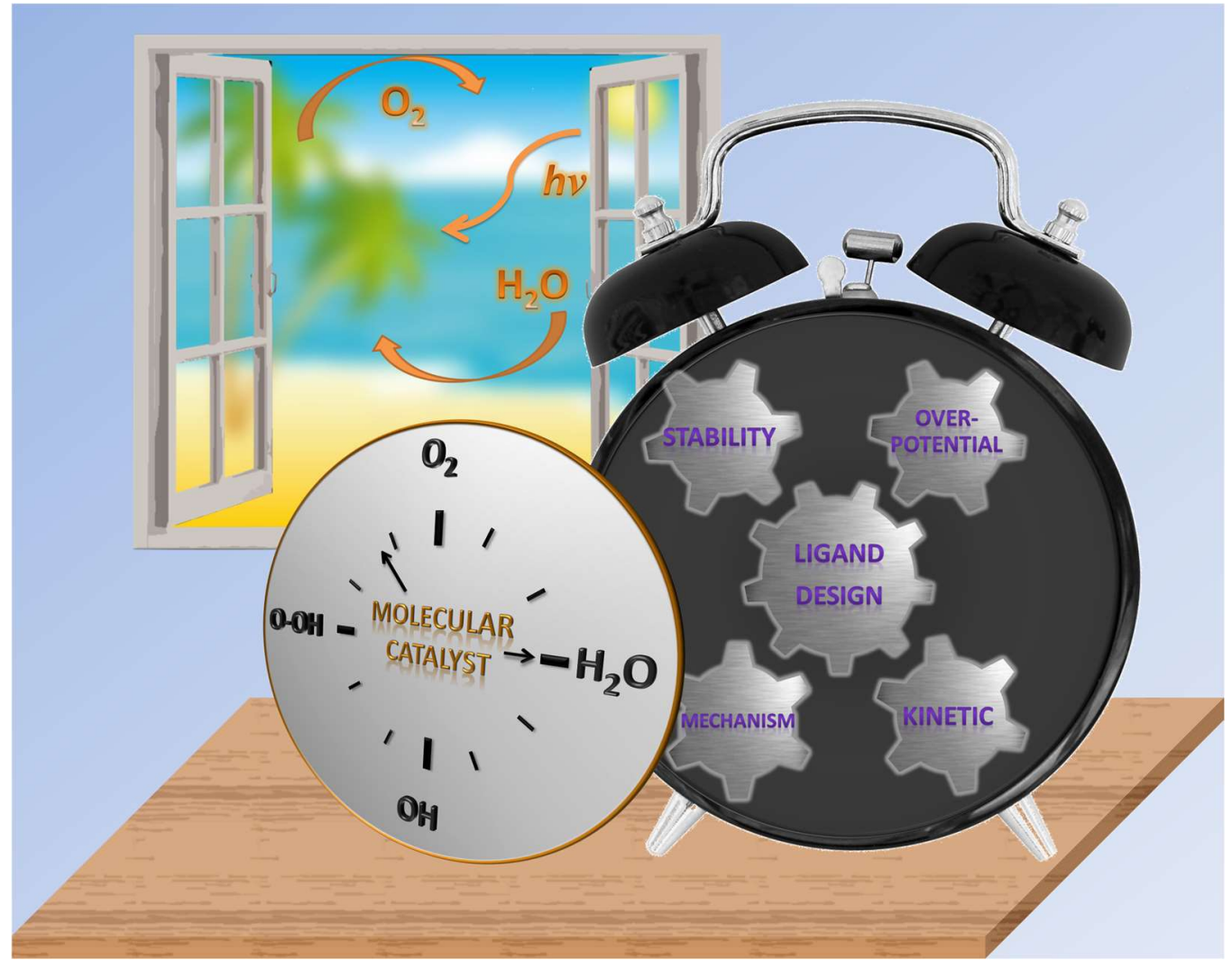


Biographical information

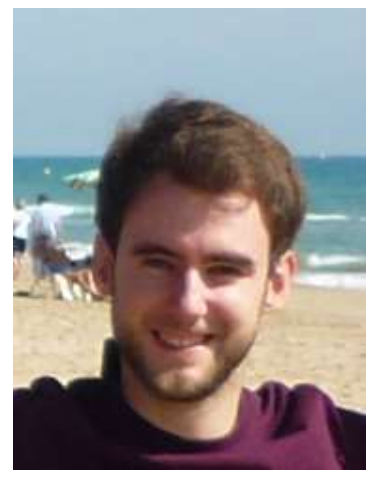

Pablo Garrido Barros graduated in Chemical Engineering at the University of Granada in 2013. In 2014, he obtained a Master Degree in Synthesis, Catalysis and Molecular Design from University Rovira i Virgili. Then he joined Prof. Antoni Llobet group at the Institute of Chemical Research of Catalonia (ICIQ) as a graduate student where he has been working on the development of water oxidation catalysts.

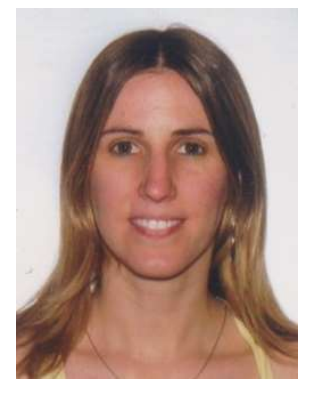

Carolina Gimbert Suriñach obtained her Ph.D. from the Autonomous University of Barcelona (UAB) in 2008. After one year as assistant professor in the same university, she moved to the University of New South Wales (UNSW) to undertake post-doctoral research. In 2012 she joined Prof. Antoni Llobet's team at the Institute of Chemical Research of Catalonia (ICIQ), where she is working on hydrogen evolving and water oxidation photocatalysis for water splitting.

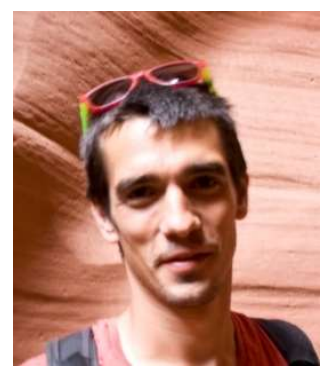

Roc Matheu obtained his bachelor degree in Chemistry from Autonomous University of Barcelona in 2012. The same year he joined Prof. Antoni Llobet group at the Institute of Chemical Research of Catalonia (ICIQ) to develop molecular water oxidation catalysts as a graduate student. 


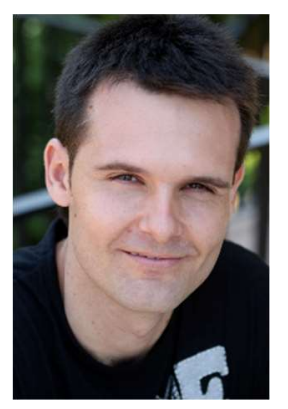

Xavier Sala obtained his Ph.D. in Chemistry from the University of Girona in 2007. After postdoctoral research with P. W. N. M. van Leeuwen and A. Llobet at ICIQ, he is currently Associate Professor of Chemistry at the Autonomous University of Barcelona (UAB) where he leads the Selective Oxidation Catalysis (SelOxCat) research group.

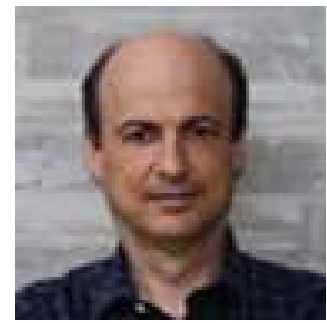

Antoni Llobet received a Ph.D. from UAB. Then he was a Postdoctoral Fellow at the University of North Carolina with T. J. Meyer and at Texas A\&M University with D. T. Sawyer and A. E. Martell. He is currently a Professor of Chemistry at UAB and Group Leader at ICIQ. 


\begin{abstract}
Energy has been a central subject for human development from Homo erectus till today. The massive use of fossil fuels during the last 50 years has generated large $\mathrm{CO}_{2}$ concentration in the atmosphere that has led to the so-called global warming. It is very urgent to come up with C-neutral energy schemes to be able to preserve Planet Earth for future generations to come and still perverse our modern societies life style. One of the potential solutions is water splitting with sunlight (hv-WS) that is also associated with "artificial photosynthesis", since its working mode consists on light capture followed by water oxidation and proton reduction processes. The hydrogen fuel generated in this way is named as "solar fuel". For this set of reactions, the catalytic oxidation of water to dioxygen is one of the crucial processes that need to be understood and mastered in order to build up potential devices based on hv-WS. This tutorial describes the different important aspects that need to be considered to come up with efficient and oxidatively robust molecular water oxidation catalysts (Mol-WOCs). It is based on our own previous work and completed with essential contributions from other active groups in the field. We aim mainly at describing how the ligands can influence the properties of the MolWOCs and showing a few key examples that overall provide a complete view of today's understanding in this field.
\end{abstract}

\title{
Key Learning Points box
}

1. Controlling redox properties of transition metal complexes

2. Designing complexes that can access reactive high oxidation states

3. Visualize potential mechanism for the water oxidation reactions

4. Essential tools to characterize catalytic water oxidation reactions

5. Description of deactivation paths that need to be avoided 


\section{Index}

1. Introduction

2. Access to High Oxidation State Species and Redox Potentials

3. O-O Bond Formation Paths

4. Redox Non-Innocent Ligands

5. Intermediate Characterization

6. Main Deactivation Pathways

7. Conclusions

8. Acknowledgments

9. References 


\section{Introduction}

The capacity to control fire (energy) by early humans triggered human evolution. Fire provided not only a source of heat but also of protection and a method for cooking. As a whole it generated a turning point in human culture and development. Evidence for the use of fire in a controlled manner by Homo erectus dates from 400.000 years ago. ${ }^{1}$ Since then energy has played a major role in the development of societies as is the case of the steam engine in the industrial revolution powered by carbon and the conception of our modern societies fueled mainly by carbon, natural gas and oil. ${ }^{2}$ A common feature of mankind history is the use of bio mass and fossil fuels to generate energy that in turn produces $\mathrm{CO}_{2}$, a greenhouse gas. The massive burning of fossil fuels during the last 50 years has produced a large $\mathrm{CO}_{2}$ concentration in the atmosphere that is responsible for today's global warming and the catastrophic consequences associated with the latter. $^{3}$

In order to preserve Planet Earth it is imperative that our modern societies shift from fossil to Cneutral energy sources and thus new sustainable and environmentally respectful energy conversion schemes are needed.

Water splitting with sunlight ( $h v-W S$ ) is one of these potential respectful solutions and fits within the concept of energy democracy. ${ }^{4}$ It consists on the simultaneous oxidation and reduction of water to form dioxygen and dihydrogen respectively, as indicated in the equation 1 ,

$\mathrm{H}_{2} \mathrm{O}+\mathrm{H}_{2} \mathrm{O} \stackrel{\mathrm{hv}}{\rightarrow} \mathrm{O}_{2}+2 \mathrm{H}_{2} \quad \Delta G^{\circ}=113.5 \mathrm{kcal} / \mathrm{mol}$

This reaction is uphill thermodynamically and thus ideally should be driven by sunlight. In this respect this implies storing solar energy into chemical bonds. This is analogous to the photosynthetic process carried out by green plants and algae where carbohydrates, $\mathrm{C}_{6} \mathrm{H}_{12} \mathrm{O}_{6}{ }^{5}$ are obtained from $\mathrm{CO}_{2}$ and water as shown in equation 2 ,

$6 \mathrm{CO}_{2}+6 \mathrm{H}_{2} \mathrm{O} \rightarrow \mathrm{C}_{6} \mathrm{H}_{12} \mathrm{O}_{6}+6 \mathrm{O}_{2} \quad \Delta G^{\circ}>0$

To be able to carry out these reactions successfully both in Nature and in hv-WS a number of conditions need to be met. First, neither $\mathrm{H}_{2} \mathrm{O}$ nor $\mathrm{CO}_{2}$ absorb sunlight of sufficient energy to be able to break the needed bonds and thus an alternative mechanism will be needed. In Nature chlorophylls are responsible of absorbing sunlight and produce a charge separation state that is followed by oxidative and reductive processes properly catalyzed. In the oxidation site for the water oxidation reaction (equation 3), Nature uses the Oxygen Evolving Center (OEC) at the 
Photosystem-II (PSII) as a catalyst, a $\mathrm{Mn}_{4} \mathrm{O}_{4} \mathrm{Ca}$ cluster whose structure is still a matter of debate today, ${ }^{5}$

$\mathrm{H}_{2} \mathrm{O}+\mathrm{H}_{2} \mathrm{O} \rightarrow \mathrm{O} 2+4 \mathrm{e}^{-}+4 \mathrm{H}^{+} E^{\circ}=1.23 \mathrm{~V}$ vs. SHE at $\mathrm{pH}=0$

The water oxidation catalyst is thus one of the key elements of the whole process that provides a fast conversion of water to dioxygen at a relatively low overpotential. In a similar manner a successful water splitting device using sunlight will need an efficient and robust water oxidation catalyst.

Regarding man made water oxidation catalysts there are mainly two different type of compounds used for this purpose namely, molecular catalysts and oxides. The capacity of oxides to carry out water oxidation to dioxygen electrocatalytically can be traced as far back as 1902 on the work of Cohen and Glazer. ${ }^{6}$ On the other hand, well defined molecular water oxidation catalysts (MolWOCS) capable of oxidizing water to dioxygen needed the development of coordination chemistry and thus were not discovered until 1982 by TJ Meyer. ${ }^{7}$ The present review is solely devoted to Mol-WOCs.

Most of the knowledge we have today about Mol-WOCs comes mainly from detailed, electrochemical, mechanistic and reactivity studies that have been carried out using Ru complexes. ${ }^{8}$ However, this information extracted from Ru complexes, can be carefully extrapolated to other transition metal catalysts. For this reason, the following discussion will be mainly based on Ru complexes but where appropriate we will also introduce other relevant transition metal complexes.

The objective of the present review is not to give a comprehensive description of all the molecular complexes that have been described in the literature capable of oxidizing water to dioxygen but to describe the key elements that give a consistent and rational understanding of the phenomena that contribute into the water oxidation catalysis and thus allow to come up with a unified description. Therefore, the following is an account of how ligands and transition metal geometry influence reactivity.

\section{Access to high oxidation state species and redox potentials.}

The four electrons four protons nature of the water oxidation catalysis (equation 3 ) implies necessarily that the catalyst will need to act as a reservoir of holes so that at a sufficiently high oxidation states will be able to oxidize water to dioxygen by accepting 4 electrons. Subsequent removal of "electrons-only" from a transition metal complex by simple outer sphere electron transfer can generate high oxidation states. However, upon removal of electrons-only the 
Coulombic charge generated at the metal center will produce oxidized complexes of very high energy that will not be useful for subsequent electron removal. On the other hand, the removal of protons and electrons at the same time, by proton coupled electron transfer (PCET), allows to reach highly reactive high oxidation states at a relatively low energy. An early example where this phenomenon is occurring is the Ru-aquo polypyridyl complex, $\left[\mathrm{Ru}(\mathrm{L} 1)(\mathrm{H}-\mathrm{L} 2)\left(\mathrm{H}_{2} \mathrm{O}\right)\right]^{2+}, \mathbf{1}^{1},{ }^{9}$ (see Chart 1 and 2 for ligand labeling), where a couple of PCET processes occur at $\mathrm{pH}=7$ as shown in the equation 4 , where the auxiliary polypyridyl ligands are not shown.

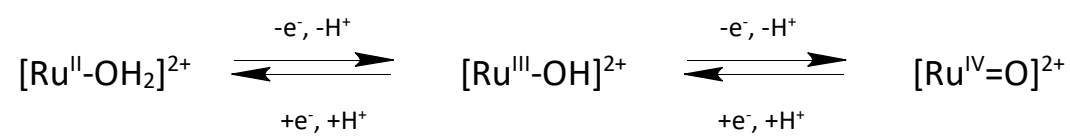

A complete description of the dominant species depending on the degree of oxidation and protonation can be graphically represented in the corresponding Pourbaix diagram depicted in Figure 1 for 1.

In this particular case the removal of protons and electrons from the $\mathrm{Ru}^{\prime \prime}-\mathrm{OH}_{2}$ group allows generating high oxidation states species with a constant overall charge. In the specific case of $\mathrm{Ru}^{\mathrm{IV}}=\mathrm{O}$, this species is further stabilized by the $\sigma$ - and $\pi$-donating ability of the oxo group. In order to easily track electron content, all the metal oxidation states in this report are described as "formal" oxidation states. However, and obviously, for all the aquo transition metal complexes discussed here the oxygen atom of the M-O group will also be responsible for partial electron density removal upon oxidation, at formal oxidation states above III. Further, all the redox potentials discussed in this review are reported versus Normal Hydrogen Electrode (NHE). The same PCET phenomenon also occurs with other transition metal complexes and thus the principles described here are also valid for these complexes. Indeed nature also uses the same trick in a number of oxidative metalloproteins ${ }^{9}$ as well as in the OEC-PSII case where each of the four electron removal in the Kok cycle is accompanied by proton removal. ${ }^{5}$

In this respect is vital to understand how electronic perturbations exerted by the ligands can influence the electron density at the metal center and thus its redox potentials. ${ }^{10,11} \mathrm{An}$ enlightening example is described in a series of Ru-aquo complexes containing the trispyrazolyl tridentate facial ligand $\mathrm{L} 4$ and substituted 2,2'-bipyridine (bpy) of general formula, [Ru"(L4)(X$\left.\mathrm{L2})\left(\mathrm{H}_{2} \mathrm{O}\right)\right]^{2+},\left(\mathrm{X}=\mathrm{H}, 2 ; \mathrm{X}=\mathrm{NO}_{2}, \mathbf{3} ; \mathrm{X}=\mathrm{NH}_{2}, 4\right)$, where the addition of electron donating groups produces an increase on electron density on the metal center whereas the electron withdrawing groups do just the opposite. Thus the formers produce a decrease of the redox potential whereas the latters increase them. These trends are illustrated in Figure 2 where a plot of the IV/III and III/III redox couples for complexes 2-4 is offered. Interestingly, the influence at the two different redox potentials is not of the same magnitude. Indeed, as can be seen in Figure 2, while the III/II redox couple is strongly influenced the IV/III is much less affected. As such this means that with 
sufficiently strong electron withdrawing groups attached at the bpy ligands we should be able to generate complexes where a single two-electron process should occur.

An additional important aspect to be understood is how ligand $\sigma$ - and $\pi$-perturbation influence the redox potentials of the different redox couples. In this sense it is enlightening to observe the plot of $\Delta E_{1 / 2}=E_{1 / 2}(\mathrm{IV} / \mathrm{III})-E_{1 / 2}(\mathrm{III} / \mathrm{II})$ against the Lever parameter ${ }^{12}$ as indicated in Figure 3 . As can be observed here both the sigma donating ligands and pi-accepting ligands align but at two different zone of the diagram and suggest that the right combination of $\sigma$ - and $\pi$-perturbation should lead to access the $\Delta E_{1 / 2}<0$ zone. Indeed, the right combination of pyridyl and carbene ligands in $\left[R u^{\prime \prime}(\mathrm{L} 5)(\mathrm{L} 6)\left(\mathrm{H}_{2} \mathrm{O}\right)\right]^{2+}, 14$, allows to obtain $\mathrm{Ru}^{\mathrm{IV}}=\mathrm{O}$ complexes that behave as a two-electron acceptor. This is nicely applied to the epoxidation of cis-alkenes to their corresponding cisepoxides by $\mathbf{1 4}$, where the two-electron transfer favors the concerted mechanism and in turn favors the stereoselectivity of the reaction. ${ }^{11}$

For Ru-aquo complexes containing neutral polypyridyl type of ligands such as in 1, there is an additional oxidation redox process that is a simple outer sphere electron transfer (OSET) process with no proton coupling that corresponds to the V/IV redox couple, as shown in the Pourbaix diagram in Figure 1. In a number of Ru-aquo complexes containing pyridyl ligands, this high oxidation state is responsible for a suite of events that end up making dioxygen. ${ }^{13,14}$ It is thus very important to understand how electronic perturbation on ligands can influence the redox potential of the $\mathrm{Ru}^{\mathrm{V}} / \mathrm{Ru}^{\mathrm{IV}}$ couple.

An example that illustrates this ligand effects is the comparison of the redox potentials of two Ru complexes containing the bpy-dicarboxylato ligand L132-, [Ru"(L13)(MeO-L14)], 15, and $\left[R u^{\prime \prime}(\mathrm{L} 13)(\mathrm{L} 15)\right]^{+}, 16 .{ }^{15}$ For 15 , containing an axial isoquinoline ligand with a strong electron donating group (MeO-L14) the potentials appear at: V/IV $=0.69 \mathrm{~V}, \mathrm{IV} / \mathrm{III}=0.48 \mathrm{~V}$ and III/II $=0.01 \mathrm{~V}$. Whereas for 16, containing a methylated pyridyl group, L15, the potentials appear at: $\mathrm{V} / \mathrm{IV}=0.70$ $\mathrm{V}, \mathrm{IV} / \mathrm{III}=0.48 \mathrm{~V}$ and III/II $=0.18 \mathrm{~V}$. Comparing these values clearly show that the remote electronic perturbation through the $\pi$-system strongly affects the III/II potential but affects very little the IV/III and V/IV potentials. This is frustrating from a catalytic perspective because the latter couple is the most important one, associated with the overpotential of the electrocatalysis. This is due to the fact that the higher the oxidation state the lower will be the participation of the axial pyridyl auxiliary ligands in the HOMO/SUMO orbitals and thus this remote influence will be negligible. In other words, above oxidation sate III for Ru, the removal of electron density to generate high oxidation states will be predominantly occurring from the oxygen of the Ru-O group.

Another strategy to generate reactive high oxidation state species involves the use of sufficiently electron withdrawing groups so that he $\mathrm{Ru}(\mathrm{IV})=\mathrm{O}$ species has a IV/III redox potential higher than that of the water oxidation thermodynamic value and thus is habilitated to carry out water oxidation. This is the case of complex $\left[\mathrm{Ru}^{\prime \prime}(\mathrm{L} 1)(\mathrm{L} 16)\left(\mathrm{H}_{2} \mathrm{O}\right)\right], 17$, that contains a carboxylato moiety as electron withdrawer and whose IV/III couple is $0.90 \mathrm{~V}$ at $\mathrm{pH}=7$. Indeed, this complex at oxidation state IV oxidizes water to dioxygen although it occurs very slowly. ${ }^{16}$ Another option that manifests the richness of the reactivity of Ru complexes is the capacity of Ru(IV) species to 
disproportionate into $\mathrm{Ru}(\mathrm{III})$ and its highly active $\mathrm{Ru}(\mathrm{V})$ counterparts. The latter, as indicated above, is a highly active species that can foster the formation of dioxygen. This has been proposed to occur in $\left[\mathrm{Ru}(\mathrm{L} 1)(\mathrm{H}-\mathrm{L} 17)\left(\mathrm{H}_{2} \mathrm{O}\right)\right]^{2+}, \mathbf{1 8} .^{17}$

\section{O-O Bond formation paths}

From a phenomenological perspective the formation of an oxygen-oxygen bond can occur via the so-called water nucleophilic attack mechanism (WNA) or by interaction of two M-O units (I2M) that is illustrated in Figure 4 for the case of Ru-Hbpp, the complex containing the dinucleating

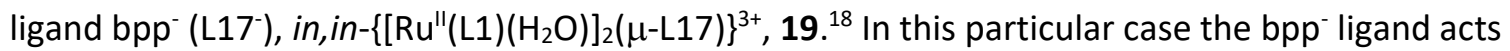
as an scaffold that preorganizes and properly places the two $\mathrm{Ru}^{\prime \prime}-\mathrm{OH}_{2}$ groups so that after losing $4 \mathrm{H}^{+}$and $4 \mathrm{e}^{-}$, the corresponding $\mathrm{Ru}^{\mathrm{IV}}=\mathrm{O}$ groups can form the $\mathrm{O}-\mathrm{O}$ bond, which in this way is entropically favored. In this case, all the experimental evidences point toward the $12 \mathrm{M}$ mechanism. The mechanistic elucidation includes the use of spectroscopic techniques, kinetic analysis and reactivity tests. Particularly useful are the labeling experiments where the Ru-aquo complexes and the solvent $\mathrm{H}_{2} \mathrm{O}$ contain ${ }^{18} \mathrm{O}$ with a different degree of labeling. This allows to differentiate unambiguously between the two pathways by the use of mass spectrometry, just checking the molecular weight of the $\mathrm{O}_{2}$ generated in the first turnover as shown in Figure 4. This strategy has been carried out in a number of occasions and produces extremely valuable information from a mechanistic perspective. ${ }^{19}$ The energy difference between those two mechanisms calculated by Density Functional Theory (DFT) is of $9.1 \mathrm{kcal} / \mathrm{mol}$ and is basically dictated by the reactivity of the Ru-O group. In all cases studied the energy differences are large enough so that there is no mixing of the two mechanisms but there is no reason why a particular combination of auxiliary ligands could generate a reactive species that could go both ways.

Further, in this mechanism it is important to realize the importance of solvent $\mathrm{H}_{2} \mathrm{O}$ as proton acceptor in the $\mathrm{O}-\mathrm{O}$ bond formation step where a Ru-OOH intermediate is formed. Indeed, a DFT analysis shows how a gas phase study in the absence of solvent water, changes the relative energies of the two pathways favoring the WNA mechanism. ${ }^{20}$ The influence of the base in the O$O$ bond formation step has also been clearly put forward in elegant studies using different external bases. In this way, depending on the strength of the base, the rate constant increase by 5 orders of magnitude from water to $\mathrm{HO}^{-21}$ In a recent work it has also been shown a spectacular effect on kinetics when the base used was judiciously situated in the ligand framework so that it works in an intramolecular manner. ${ }^{22}$

A change from intramolecular $12 \mathrm{M}$ to intermolecular 12M occurs when the meridional trpy, L1 ligand in 19, is replaced by the facial tridentate ligands L4 or L18. This produces a change in the relative disposition of the two Ru-aquo groups within the complex from in, in to trans, as in trans$\left\{\left[\mathrm{Ru}^{\prime \prime}(\mathrm{L} 18)\left(\mathrm{H}_{2} \mathrm{O}\right)\right]_{2}(\mu-\mathrm{L} 17)\right\}^{3+}, \mathbf{2 0}$, and thus constitutes an example of how ligand design can strongly influence reactivity. ${ }^{23}$ 
A remarkable catalyst whose $\mathrm{O}-\mathrm{O}$ bond formation occurs by an intermolecular $12 \mathrm{M}$ mechanism is the Ru-bda complex, [Ru"(L13)(Me-L3)], 21. ${ }^{24}$ This catalyst contains a flexible ligand framework that adapts to the electronic demands of the different oxidation states. Thus at oxidation state II the complex has coordination number 6 in a pseudo-octahedral geometry but at oxidation states IV and $\mathrm{V}$ it becomes 7 coordinate adopting a pentagonal bipyramid geometry. Interestingly under restricted mobility conditions the complex can't dimerize but still can carry out the oxidation of water to dioxygen by shifting to higher energy pathways based on the WNA mechanism. This however produces catastrophic consequences with regard to the ligand stability as will be discussed in the next section. ${ }^{25}$ Interestingly a recently reported cyclic trimer based on the Ru-bda complex, $\left[R u^{\prime \prime}(\mathrm{L} 13)(\mathrm{L} 21)\right]_{3}, \mathbf{2 2}$, generates a very robust structure that also changes the mechanism from I2M to WNA and maintains the stability of the ligand framework. ${ }^{26}$ Similarly this is achieved with complex $\left\{\left[\mathrm{Ru}(\mathrm{H}-\mathrm{L} 3)_{2}\left(\mathrm{H}_{2} \mathrm{O}\right)\right](\mu-\mathrm{L} 20)\right\}^{3+}, \mathbf{2 3}$, that has a very similar arrangement as in in,in$\left\{\left[\mathrm{Ru}^{\prime \prime}(\mathrm{L} 1)\left(\mathrm{H}_{2} \mathrm{O}\right)\right]_{2}(\mu-\mathrm{L} 17)\right\}^{3+}, 19$, but the extra pyridyl groups at $\mathrm{L} 20$ with regard to $\mathrm{L} 17$, place the two metal centers sufficiently apart to one another, so that the mechanism also changes from I2M to WNA. ${ }^{19}$

\section{Redox non-innocent ligands.}

Transition metal complexes that undergo redox events at the ligand have been flourishing lately after the pioneering work of Wieghardt and others. ${ }^{27}$ For the water oxidation reaction that involves multiple electron and proton removal, the option of sharing the burden to reaching high oxidation states between the metal and the ligand is certainly an attractive concept.

A Ru-aquo catechol complex reported in 2009, [Ru" $\left.(\mathrm{L} 1)(\mathrm{L} 22)\left(\mathrm{H}_{2} \mathrm{O}\right)\right], \mathbf{2 4}$, has been shown to access a number of different oxidation states based on pulse radiolysis coupled to electrochemical experiments and supported by DFT calculations. ${ }^{28}$ It is shown that by progressive electron removal there is an interplay of metal and ligand oxidation, identifying the corresponding Ru semiquinone and quinone complexes as a function of $\mathrm{pH}$. Recently an anionic $\mathrm{Cu}(\mathrm{II})$-amidate complex, $[\mathrm{Cu}(\mathrm{L} 23)]^{2-}, \mathbf{2 5}$, has been reported where after the initial metal based III/II oxidation it suffers an additional oxidation at the ligand basically forming a phenyl radical cation. While the latter is a reversible process in dry organic solvents it is responsible for a large electrocatalytic wave in the presence of water, due to the oxidation of the latter to dioxygen. Remarkably this ligand oxidation event is chemically reversible thanks to the fast catalytic reaction. ${ }^{29}$ Further, the use of electron donating groups at the aromatic ring allows to strongly fine tune the electronic properties of this radical cation. Using a dimethoxy substitution allows to achieve the record low overpotential for first row transition metal based water oxidation catalysts of $170 \mathrm{mV}$ at $\mathrm{pH}=11.5$.

These examples show how the right combination of metal and ligand based oxidation can exert an extraordinary electronic control at the different redox processes involved in the water oxidation process and particularly and remarkably to the most important process that is responsible for the rate determining step. 


\section{Intermediate characterization.}

The characterization of reaction intermediates in any catalytic cycle is one of the fundamental keys for the understanding of reaction mechanisms. For many Ru complexes the electrochemical and spectroscopic experiments allow to characterize several intermediates as is the case for instance of complex 1, whose Pourbaix diagram is shown in Figure 1. However, the most interesting intermediate species, the $\mathrm{RuOOH}$, still remains ill characterized although some attempts have been carried out recently for $\left[\mathrm{Ru}(\mathrm{L} 19)(\mathrm{L} 24)\left(\mathrm{H}_{2} \mathrm{O}\right)\right]^{2+}, \mathbf{2 6},{ }^{30}$ and $\left[(\mathrm{L} 1)(\mathrm{H}-\mathrm{L} 2) \mathrm{Ru}^{\mathrm{III}}-\mathrm{O}-\mathrm{Ru} \mathrm{u}^{\mathrm{III}}(\mathrm{L} 1)(\mathrm{O})\left(\mathrm{H}_{2} \mathrm{O}\right)\right]^{4+}$, 27. ${ }^{31}$ In this respect the best technique for the characterization of a peroxide and/or superoxide is undoubtedly vibrational spectroscopy through infrared and/or Raman spectroscopy using labeled oxygen atoms to identify the O-O bond vibration. For the case of the Ru complexes this vibration is difficult to characterize because it is very weak and shows unexpectedly low isotopic shifts with ${ }^{18} \mathrm{O}$. According to DFT the weakness of these signals is due to low Raman activity of the vibrational modes involved and the small shifts suggest a distribution of the O-O stretching coordinates among several modes. ${ }^{30,31}$ In sharp contrast, for the Co-Hbpp water oxidation catalyst, $\left\{\left[\mathrm{Co}^{\prime \prime}(\mathrm{L} 1)\left(\mathrm{H}_{2} \mathrm{O}\right)\right]_{2}(\mu-\mathrm{L} 17)\right\}^{3+}, \mathbf{2 8},{ }^{32}$ both the peroxo and superoxo complexes before oxygen is generated have been beautifully identified by resonance Raman (rR) spectroscopy (see Figure 5) and also by a number of additional spectroscopic techniques including Nuclear Magnetic Resonance (NMR), Electron Paramagnetic Resonance (EPR), Cyclic Voltammetry (CV), X-ray Absorption Spectroscopy (XAS) and further complemented with DFT calculations.

Labelling experiments also give crucial evidence especially with regard to the O-O bond formation mechanism as has been described above for Ru complexes. One of the key aspects to be able to extract meaningful information for this type of experiments is the substitution kinetics of the bonded Ru aquo or hydroxido groups by solvent water. For Ru complexes this process has been successfully slowed down upon reaching high oxidation states. ${ }^{18}$ For first row transition metal complexes there is only one example, the $\mathrm{Ru}_{2} \mathrm{Co},\left\{\left[(\mathrm{L} 1)\left(\mathrm{H}_{2} \mathrm{O}\right) \mathrm{Ru}\right]_{2}\left[\mu-\mathrm{Co}\left(\mathrm{H}_{2} \mathrm{O}\right)_{2}(\mathrm{~L} 17)_{2}\right]\right\}^{4+}, \mathbf{2 9},{ }^{33}$ where this type of experiments have been performed. In this case the labeling experiments carried out together with the rest of the electrochemical and spectroscopic properties are in agreement with the presence of a water nucleophilic WNA mechanism occurring at the Co site of the trinuclear complex, with cooperative interaction of the two Ru sites via electronic coupling through the bpp (L17') bridging ligand and via neighboring hydrogen bonding.

\section{Main deactivation pathways}

As indicated in equation 3 , the thermodynamic potential at which water oxidation occurs is $1.23 \mathrm{~V}$, which is very high. Thus any catalyst that can oxidize water will oxidize a whole variety of organic substrates. Therefore, it is imperative to use complexes containing ligands that are not easily oxidized or that are oxidized at a sufficiently slow rate so that its degradation is negligible. It is only under these conditions that meaningful information can be extracted, otherwise the main 
information extracted is related to the ligand oxidation and/or oxide nanoparticle formation, rather than water oxidation by the initial molecular complex. Under these unavoidable conditions it is extremely important to check the nature of the molecular catalyst during and after the catalytic reaction. This is particularly important since the corresponding metal oxides, of the used transition metal complexes, are also active water oxidation catalysts. ${ }^{34}$

A few examples of deactivation pathways that occur in Mol-WOCs are summarized in Scheme 1 and will be discussed below.

Among the most easily oxidizable organic substrates are those containing methylenic groups in benzyls, benzyl alcohol and benzyl pyridyls (e.g. 1 in Scheme 1). Some complexes have been prepared using this groups but a careful analysis of their behavior clearly shows their degradation. Some of the many examples reported include: $\left\{\left[R u^{\prime \prime}(L 1)\left(\mathrm{H}_{2} \mathrm{O}\right)\right]_{2}(\mu-\mathrm{D} 1)\right\}^{3+}, 3{ }^{35}\left\{\left[\mathrm{Ru}^{\prime \prime}\left(\mathrm{H}_{2} \mathrm{O}\right)\right]_{2}(\mu-\right.$ $\mathrm{D} 2)\}^{3+}, \mathbf{3 1},{ }^{36}\left[\mathrm{Ru}(\mathrm{D} 3)\left(\mathrm{H}_{2} \mathrm{O}\right)\right]^{2+}, \mathbf{3 2} .{ }^{37}$ In these complexes a careful analysis simultaneously measuring the amount of $\mathrm{O}_{2}$ and $\mathrm{CO}_{2}$ generated, shows the formation of the latter from the very beginning. This implies that massive ligand degradation occurs together with the formation of $\mathrm{O}_{2}$ and thus point to the formation of $\mathrm{RuO}_{2}$ as the active species rather than the initial molecular complex. Importantly, the $\left[\mathrm{CO}_{2}\right]$ should be measured simultaneously with the generation of $\left[\mathrm{O}_{2}\right]$, since otherwise a simple measurement at the end of the reaction will contain a very low $\left[\mathrm{CO}_{2}\right]$ as compared to that of the $\left[\mathrm{O}_{2}\right]$ generated, especially if the corresponding oxide is relatively active.

Another paradigmatic error that appears constantly in the literature is to show a totally chemically irreversible redox wave in the voltammogram for a particular complex and claim that the initial complex is intact after bulk electrolysis carried out above the irreversible wave's potential. This was reported for the dinuclear Co complex $\left\{\left[\mathrm{Co}^{\prime \prime \prime}(\mathrm{D} 4)\right]_{2}(\mu-\mathrm{OH})(\mu-\mathrm{OO})\right\}^{3+}, 33^{38}$ and later shown that the only active species were $\mathrm{CoOx} .{ }^{39}$ Other related contradictory examples include $\left[\mathrm{Mn}^{\prime \prime}(\mathrm{D} 5)\left(\mathrm{H}_{2} \mathrm{O}\right)_{2}\right]^{2+}, \mathbf{3 4},{ }^{40}$ and recently $\left[\mathrm{Fe}{ }^{\prime \prime \prime}(\mathrm{D} 6)\left(\mathrm{H}_{2} \mathrm{O}\right)\right]^{-}, 35 .{ }^{41}$ In the latter case the chemical irreversibility of the waves is mostly likely due to ligand dissociation and oxide formation rather than ligand degradation since amides are relatively stable with regard to oxidative degradation.

In most of the Ru-aquo polypyridyl complexes described as water oxidation catalysts, the ligands bonded to the metal center are kinetically inert except for the aquo group where most of the chemistry is occurring. On the other hand, first row transition metals complexes based on $\mathrm{Mn}, \mathrm{Fe}$, Co or Ni contain ligands that are kinetically labile, and depending on the $\mathrm{pH}$ there will always be a significant competition between the ligand and solvent water for the coordination site of the metal center, as exemplified in the following equations for [Fe"(D8) $\left.\left(\mathrm{H}_{2} \mathrm{O}\right)_{2}\right], 36,{ }^{42}$

$$
\begin{aligned}
& {\left[\mathrm{Fe}\left(\mathrm{D} 8-\kappa-\mathrm{N}^{4}\right)\left(\mathrm{H}_{2} \mathrm{O}\right)_{2}\right]^{2+}+\mathrm{H}_{2} \mathrm{O} \rightarrow\left[\mathrm{Fe}\left(\mathrm{D} 8-\kappa-\mathrm{N}^{3}\right)\left(\mathrm{H}_{2} \mathrm{O}\right)_{3}\right]^{2+}} \\
& {\left[\mathrm{Fe}\left(\mathrm{D} 8-\kappa-\mathrm{N}^{3}\right)\left(\mathrm{H}_{2} \mathrm{O}\right)_{3}\right]^{2+}+\mathrm{H}_{2} \mathrm{O} \rightarrow\left[\mathrm{Fe}\left(\mathrm{D} 8-\kappa-\mathrm{N}^{2}\right)\left(\mathrm{H}_{2} \mathrm{O}\right)_{4}\right]^{2+}} \\
& {\left[\mathrm{Fe}\left(\mathrm{D} 8-\kappa-\mathrm{N}^{2}\right)\left(\mathrm{H}_{2} \mathrm{O}\right)_{4}\right]^{2+}+\mathrm{H}_{2} \mathrm{O} \rightarrow\left[\mathrm{Fe}\left(\mathrm{D} 8-\kappa-\mathrm{N}^{1}\right)\left(\mathrm{H}_{2} \mathrm{O}\right)_{5}\right]^{2+}}
\end{aligned}
$$


This partial decoordination can also be a source of potential ligand oxidation leading to catalyst degradation and accelerate oxide formation, as may happen in Ni complexes containing tetraazamacrocyclic type of ligands such as [Ni"(D7) ${ }^{2+}, \mathbf{3 7},{ }^{43}$ and in Fe complexes like $\left[\mathrm{Fe}^{\prime \prime}(\mathrm{D} 9)\left(\mathrm{H}_{2} \mathrm{O}\right)_{2}\right]^{2+}, \mathbf{3 8} \cdot{ }^{44,45,46} \mathrm{~A}$ recent example that most likely involves ligands substitution has been reported for a Co porphyrin complex [Co"(D10)], 39 (2, Scheme 1). This complex was initially described to act in a molecular manner but recently has been shown by Synchrotron-based Soft Xray Photoelectron Spectroscopy (SOXPES) and Hard X-ray Photoelectron Spectroscopy (HAXPES) that the active species is again CoOx. ${ }^{47}$

In some cases the ligand degradation can be partially occurring as is the case of the $\operatorname{Ir}$ complex $[\operatorname{Ir}(\mathrm{D} 11)(\mathrm{D} 12) \mathrm{Cl}], 40,{ }^{48}$ where after some controversy now the active species is proposed to be a dinuclear Ir- $(\mathrm{O})_{2}-\mathrm{Ir}$ where the D11 ligand is gone but D12 is still coordinated (3, Scheme 1$)$. Ligand degradation as indicated previously can occur all the way to $\mathrm{CO}_{2}$ and thus generating the corresponding metal oxide as active species. This active species could be part of a large aggregate typical of metal oxides generating large nanoparticles that can be detected by Dynamic Light Scattering (DLS). ${ }^{46}$ However, they can also generate the so-called "molecular oxides" depicted in Figure 6, that could be a combination of relatively low molecular weight oxides as described in the case of $\mathrm{CoOx}$ (also labeled as $\mathrm{CoPi}$; this label is unfortunate since $\mathrm{CoPi}$ does not contain $\mathrm{P}$ atoms in its structure), that will not be detectable by DLS. ${ }^{49}$ Additionally in acidic solutions discrete type of species like ferrates $\left[\mathrm{H}_{3} \mathrm{Fe}^{\mathrm{VI}} \mathrm{O}_{4}\right]^{+}$and diferrates $\left[\mathrm{H}_{4} \mathrm{Fe}^{\mathrm{VI}_{2}} \mathrm{O}_{7}\right]^{2+}$, are also known to oxidize water to dioxygen and will not be detected by DLS. ${ }^{50}$

A particularly interesting example of ligand degradation is the case of Ru-bda complex. $\left[R u^{\prime \prime}(\mathrm{L} 13)(\mathrm{D} 13)_{2}\right]^{2+}, 41$, containing the D13 axial ligands that upon reduction liberates $\mathrm{N}_{2}$ gas and anchors at graphitic surfaces making a $\mathrm{C}-\mathrm{C}$ bond. ${ }^{25}$ This is an extremely robust water oxidation catalyst in homogeneous phase that forms $\mathrm{O}-\mathrm{O}$ bonds in a bimolecular manner via an $12 \mathrm{M}$ mechanism. Attached to the surface of a graphitic electrode with restricted mobility it can't undergo dimerization. This results in the need to access high energy pathways that in parallel facilitate ligand degradation. As a result of this after a few catalytic cycles the only Ru species left at the electrode are $\mathrm{RuO}_{2}(4$, Scheme 1$) .^{25}$

Finally, during the catalytic process side reactions can occur that can lead to the suppression of the catalyst activity due to the generation of inactive species but also could generate new robust species that might be more active than the initial catalyst. This is the case of $\left[\mathrm{Ru}(\mathrm{L} 1)(\mathrm{H}-\mathrm{L} 2)\left(\mathrm{H}_{2} \mathrm{O}\right)\right]^{2+}$, $\mathbf{1}^{51}$ that slowly but irreversibly loses one of the bpy ligands generating a dinuclear Ru-O-Ru complex, $\left[(\mathrm{L} 1)(\mathrm{H}-\mathrm{L} 2) \mathrm{Ru}^{\prime \prime \prime}-\mathrm{O}-\mathrm{Ru} \mathrm{u}^{\prime \prime \prime}(\mathrm{L} 1)(\mathrm{O})\left(\mathrm{H}_{2} \mathrm{O}\right)\right]^{4+}, \mathbf{2 7}$, that is actually a better catalyst and that shows no signs of degradation after a turnover number (TON) of more than 14900 cycles $(5$, Scheme 1$) .{ }^{52}$ 


\section{Conclusions}

Molecular water oxidation catalysis is nowadays one of the most exciting challenges in coordination chemistry that if successful can provide the world with environmentally respectful energy conversion schemes based on hv-WS.

The design of Mol-WOCs encompasses the preparation of transition metal complexes that contain aquo ligands bonded to the metal center allowing to reach reactive high oxidation states at relatively low potential by PCET. Importantly this can also be achieved by the complementary involvement of redox active ligands. Once a $\mathrm{M}-\mathrm{O}$ reactive species is reached the next crucial step is the O-O bond formation that can occur via WNA or I2M. We have shown in the previous sections the important consequences this can have when the catalysts are anchored in solid supports, that in turn are necessary to simplify a potential water splitting device engineering. This mechanistic understanding, based on multiple spectroscopic, electrochemical and reactivity studies is of paramount importance in order to come up with a bottom up approach for the design of efficient WOCs.

For Mol-WOCs one of the main challenges is the intrinsically high thermodynamic redox potential that needs to be reached for the water oxidation reaction. Therefore, a Mol-WOC capable of oxidizing water will oxidize a large number of organic groups. It is thus extremely important that the ligands used to bind the metal center are kinetically robust with regard to oxidation otherwise the ligand will degrade. This will lead to oxides being responsible for water oxidation catalysis. When this happens no meaningful information can be extracted from the system and thus it becomes useless. It is surprising and excruciating to see the large amount of wrong examples published recently in the literature. Fortunately, if a judicious and careful choosing of ligands is made for the preparation of WOCs, then useful information can be obtained that allows to follow a bottom up approach. In this manner spectacular catalysts have been prepared over the last ten years that have significantly improved our knowledge in the field. For instance, the turnover frequencies (TOFs) reported over the last ten years have increased in more than 7 orders of magnitude. Indeed, we now have Mol-WOCs that operate at TOF-max that are two orders of magnitude better than that of Nature in the OEC-PSII. Also the oxidative ruggedness of the ligands has been extraordinarily improved with systems achieving turnover numbers in the range of millions.

For practical applications, system performance still needs to be improved. However, with the present knowledge, succinctly described in this review, we have most of the elements needed that judiciously used should drive us to the desired improvement in the near future, that will lead to useful devices. 


\section{Acknowledgments}

Sustained support over the last decade by MINECO and FEDER is gratefully acknowledged. The latest grants awarded are: CTQ2016-80058-R, CTQ2015-73028-EXP, CTQ2015-64261-R, SEV 20130319, ENE2016-82025-REDT (FOTOFUEL), CTQ2016-81923-REDC (INTECAT). R. M. and P. G.-B. acknowledge "La Caixa" foundation for the PhD grant. 
Figure 1. Pourbaix diagram for complex $\left[\mathrm{Ru}(\mathrm{L} 1)(\mathrm{H}-\mathrm{L} 2)\left(\mathrm{H}_{2} \mathrm{O}\right)\right]^{2+}, \mathbf{1}$, showing the variation of the different redox potentials ( $v s$. NHE) as a function of $\mathrm{pH}$. The labels indicate the zone of the predominance of the main species. Only the $\mathrm{Ru}-\mathrm{OH}_{2}$ group at the different oxidation states and different proton content is shown (auxiliary ligands $\mathrm{L} 1$ and $\mathrm{H}-\mathrm{L} 2$ are not shown). Vertical lines indicate $\mathrm{pK}_{\mathrm{a}} \mathrm{s}$. Data extracted from reference 9.

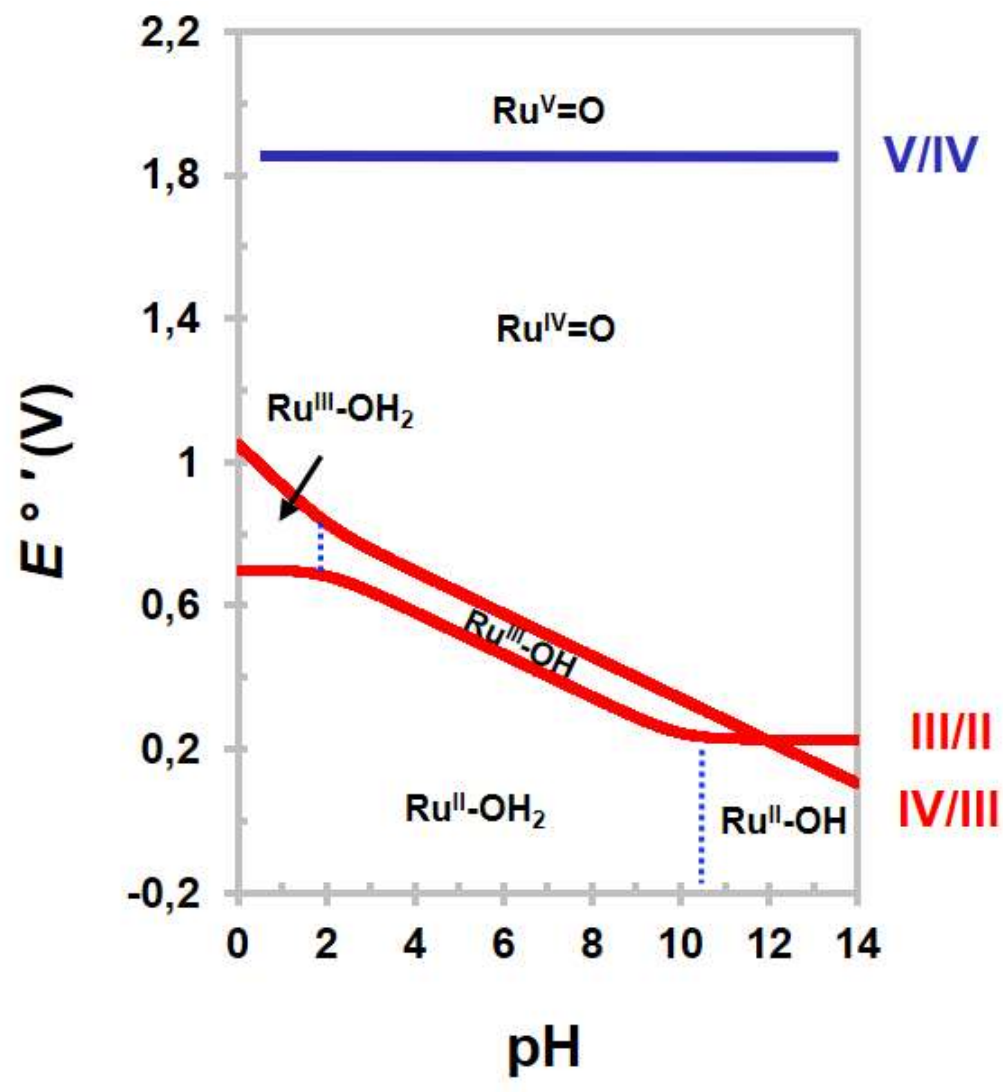


Figure 2. Graph of redox potentials for the IV/III and III/II couples in $\mathrm{V} v s$. NHE at $\mathrm{pH}=7.0$ for complexes $\left[\mathrm{Ru}^{\prime \prime}(\mathrm{L} 4)(\mathrm{H}-\mathrm{L} 2)\left(\mathrm{H}_{2} \mathrm{O}\right)\right]^{2+}, \mathbf{2}$; $\left[\mathrm{Ru}^{\prime \prime}(\mathrm{L} 4)\left(\mathrm{NO}_{2}-\mathrm{L} 2\right)\left(\mathrm{H}_{2} \mathrm{O}\right)\right]^{2+}, \mathbf{3}$ and $\left[\mathrm{Ru}^{\prime \prime}(\mathrm{L} 4)\left(\mathrm{NH}_{2}-\mathrm{L} 2\right)\left(\mathrm{H}_{2} \mathrm{O}\right)\right]^{2+}, 4$. The dark green number corresponds to $\Delta E_{1 / 2}=E_{1 / 2}(\mathrm{IV} / \mathrm{III})-E_{1 / 2}(\mathrm{III} / \mathrm{II})$ for the three complexes. Data extracted from reference 11.

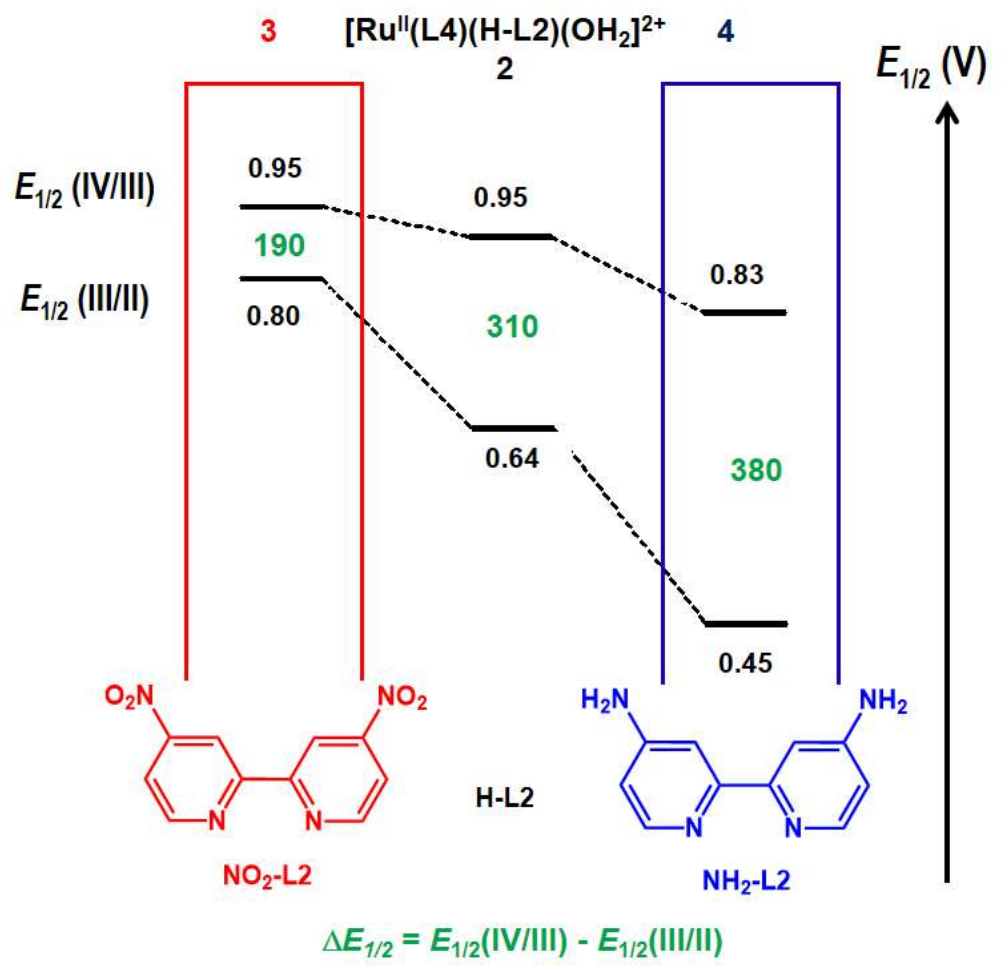


Figure 3. Plot of $\Delta E_{1 / 2}=E_{1 / 2}(\mathrm{IV} / \mathrm{III})-E_{1 / 2}(\mathrm{III} / \mathrm{II})$ vs. $\Sigma L$ for selected Ru-aquo complexes:

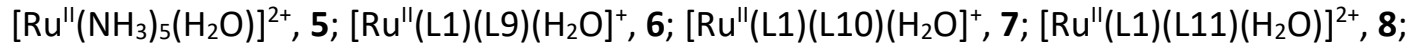

$\left[\mathrm{Ru}^{\prime \prime}(\mathrm{L} 1)(\mathrm{L7})\left(\mathrm{H}_{2} \mathrm{O}\right)\right]^{2+}, 9 ;\left[\mathrm{Ru}^{\prime \prime}(\mathrm{L} 4)\left(\mathrm{NO}_{2}-\mathrm{L} 2\right)\left(\mathrm{H}_{2} \mathrm{O}\right)\right]^{2+}, 10 ;\left[\mathrm{Ru}^{\prime \prime}(\mathrm{H}-\mathrm{L} 2){ }_{2}(\mathrm{~L} 8)\left(\mathrm{H}_{2} \mathrm{O}\right)\right]^{2+}, 11$;

$\left[\mathrm{Ru}^{\prime \prime}(\mathrm{L} 1)(\mathrm{L} 12)\left(\mathrm{H}_{2} \mathrm{O}\right]^{2+}, 12 ;\left[\mathrm{Ru}^{\prime \prime}(\mathrm{L} 5)(\mathrm{H}-\mathrm{L} 2)\left(\mathrm{H}_{2} \mathrm{O}\right)\right]^{2+}, 13 ;\left[\mathrm{Ru}^{\prime \prime}(\mathrm{L} 5)(\mathrm{L} 6)\left(\mathrm{H}_{2} \mathrm{O}\right)\right]^{2+}, 14\right.$. Data extracted from references 11 and 12 . See text for details.

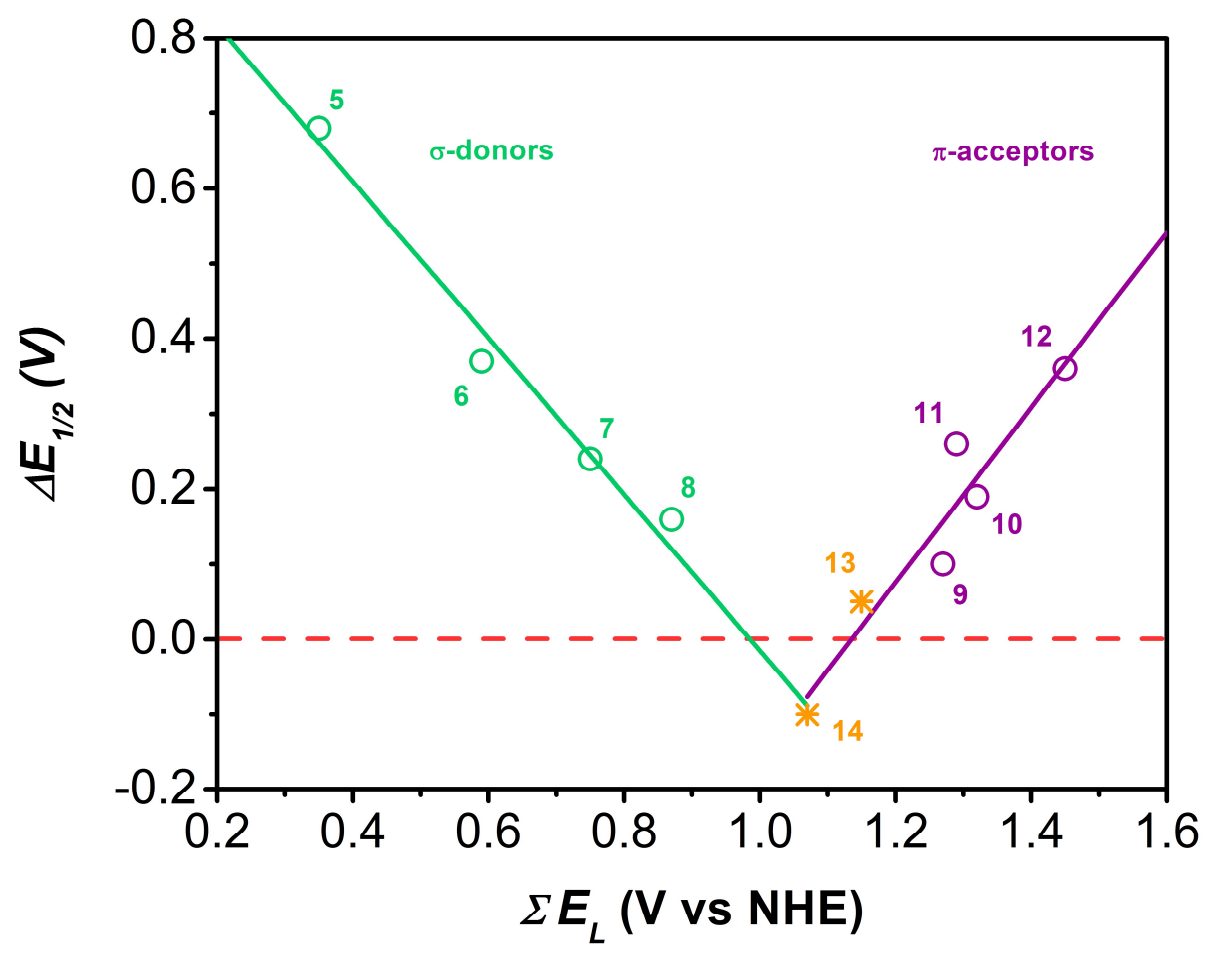


Figure 4. Two potential water oxidation reaction mechanisms involving WNA and I2M for complex in, in- $\left\{\left[\mathrm{Ru} \text { " }(\mathrm{L} 1)\left(\mathrm{H}_{2} \mathrm{O}\right)\right]_{2}(\mu-\mathrm{L} 17)\right\}^{3+}, 19$, based on experimental evidence and supported by DFT calculations. Energy values in $\mathrm{Kcal} / \mathrm{mol}$. The L1 ligands are not drawn for clarity. Red oxygens correspond to ${ }^{18} \mathrm{O}$ initially labeled catalyst whereas blue oxygens refer to the initially non-labeled solvent $\mathrm{H}_{2}{ }^{16} \mathrm{O}$. Data extracted from reference 17 .

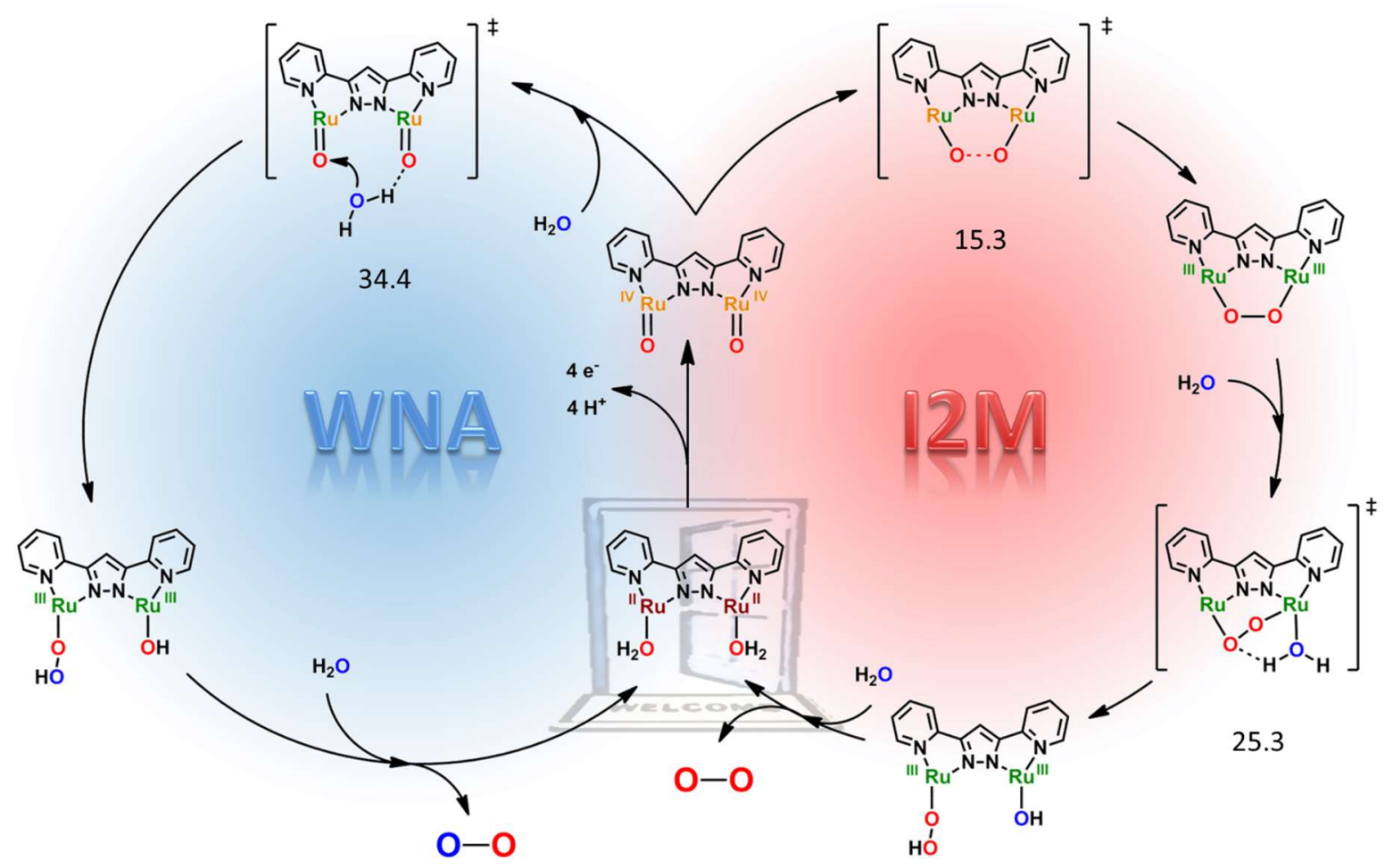


Figure 5. Normalized rR spectra for side-on peroxido, [(L1)Co $\left.{ }^{\prime \prime \prime}-(\mu-O O)(\mu-\mathrm{L} 17)-\mathrm{Co}^{\prime \prime \prime}(\mathrm{L} 1)\right]^{3+}$, and endon superoxido [( $\mathrm{L} 1)(\mathrm{OO}) \mathrm{Co}^{\prime \prime \prime}-(\mu-\mathrm{L} 17)-\mathrm{Co} \mathrm{O}^{\mathrm{II \prime}}(\mathrm{L} 1)\left(\mathrm{H}_{2} \mathrm{O}\right]^{4+}$ complexes derived from $\mathbf{2 8}$, with labeled ${ }^{16} \mathrm{O}$, ${ }^{17} \mathrm{O}$ and ${ }^{18} \mathrm{O}$ oxygen atoms. Left, black line, peroxo-32 $\left(839 \mathrm{~cm}^{-1}\right)$; blue line, peroxo-34 $\left(814 \mathrm{~cm}^{-1}\right)$, red line, peroxo-36 $\left(795 \mathrm{~cm}^{-1}\right)$. Right, black line, superoxo-32 $\left(1121 \mathrm{~cm}^{-1}\right)$; blue line, superoxo-34 $\left(1088 \mathrm{~cm}^{-1}\right)$, red line, superoxo-36 $\left(1055 \mathrm{~cm}^{-1}\right)$. The inset in the graphs show the drawn structure of the complexes omitting the trpy ligands L1. Data extracted from reference 31, asterisks indicate vibrations from solvent.
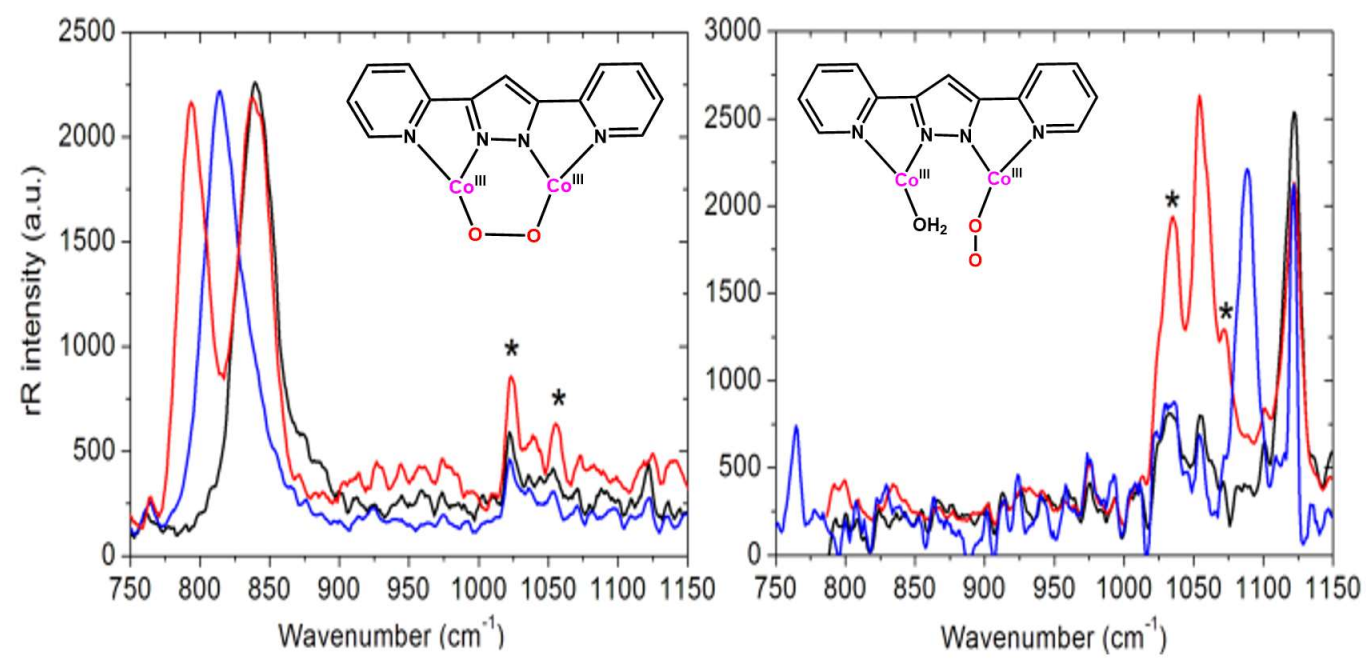
Figure 6. Drawn structures of molecular Cobalt oxides obtained from the XAS data for CoPi. Data extracted from reference 48 . Color codes: blue, cobalt; red, bridging oxygen; pink, terminal oxygen.
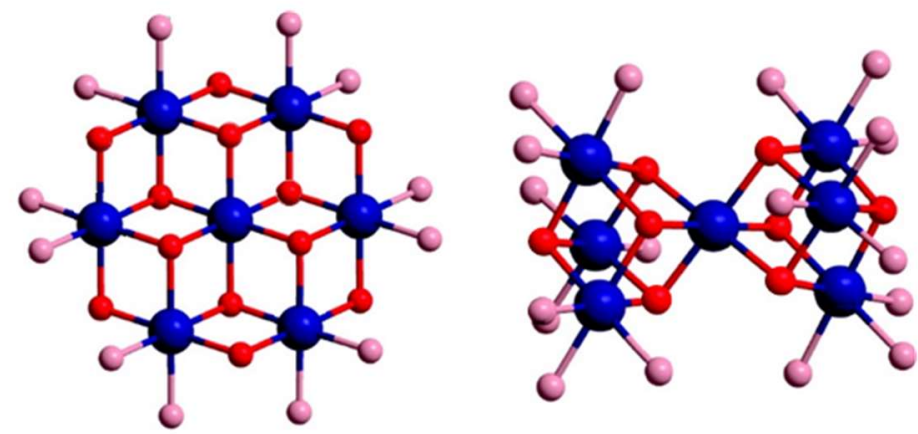
Scheme 1. Main Deactivation Pathways of water oxidation catalysts.

1. Ligand Oxidation and Oxide Formation

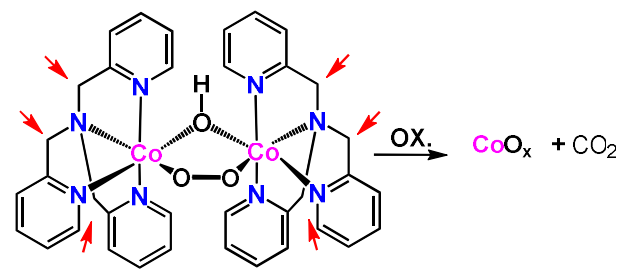

32

2. Ligand Substitution and Oxide Formation
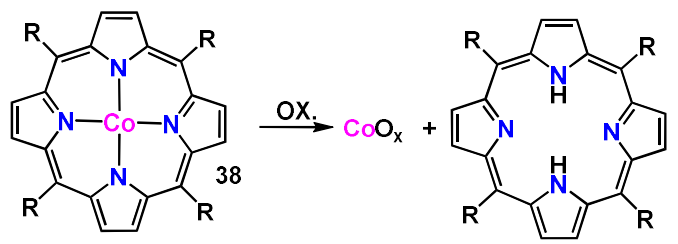

39

3. Partial Ligand Oxidation

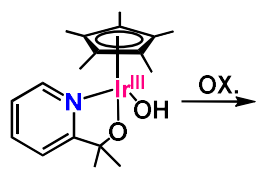

40

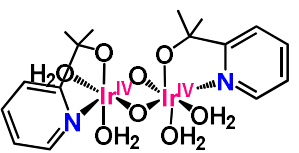

4. Translational Mobility Restrictions and Oxide Formation.

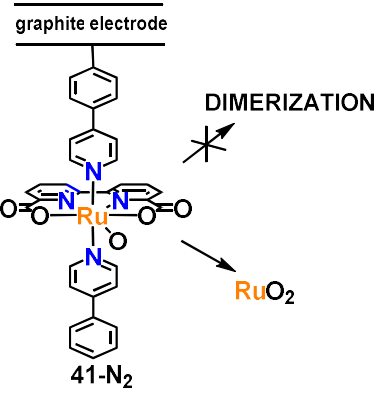

5. Complex Reorganization

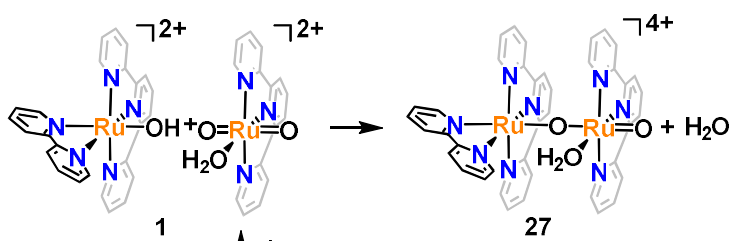

1

$\uparrow \cdot$ spy

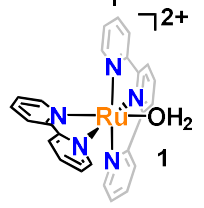


Chart 1. Ligands-I
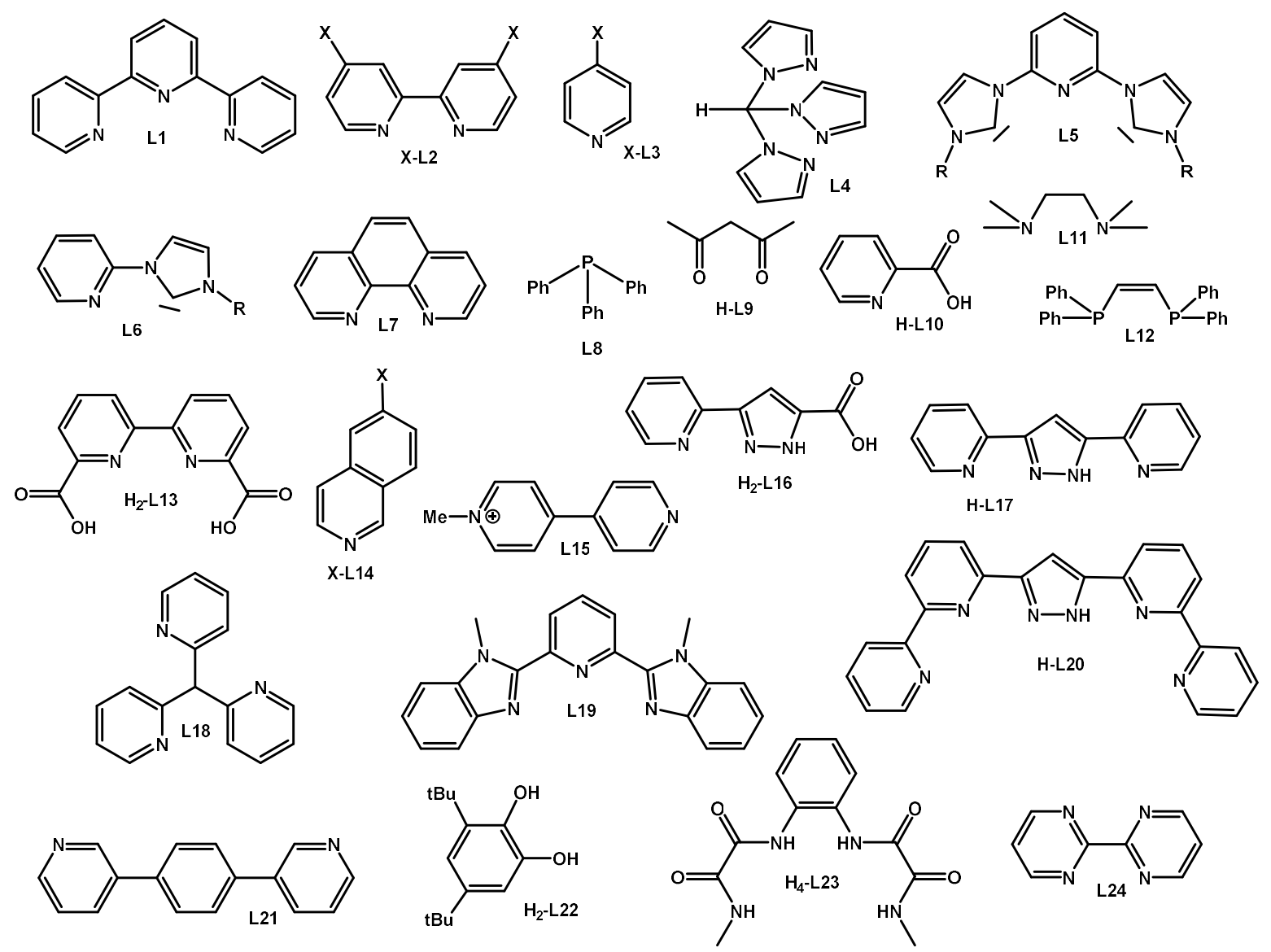
Chart 2. Ligands-II

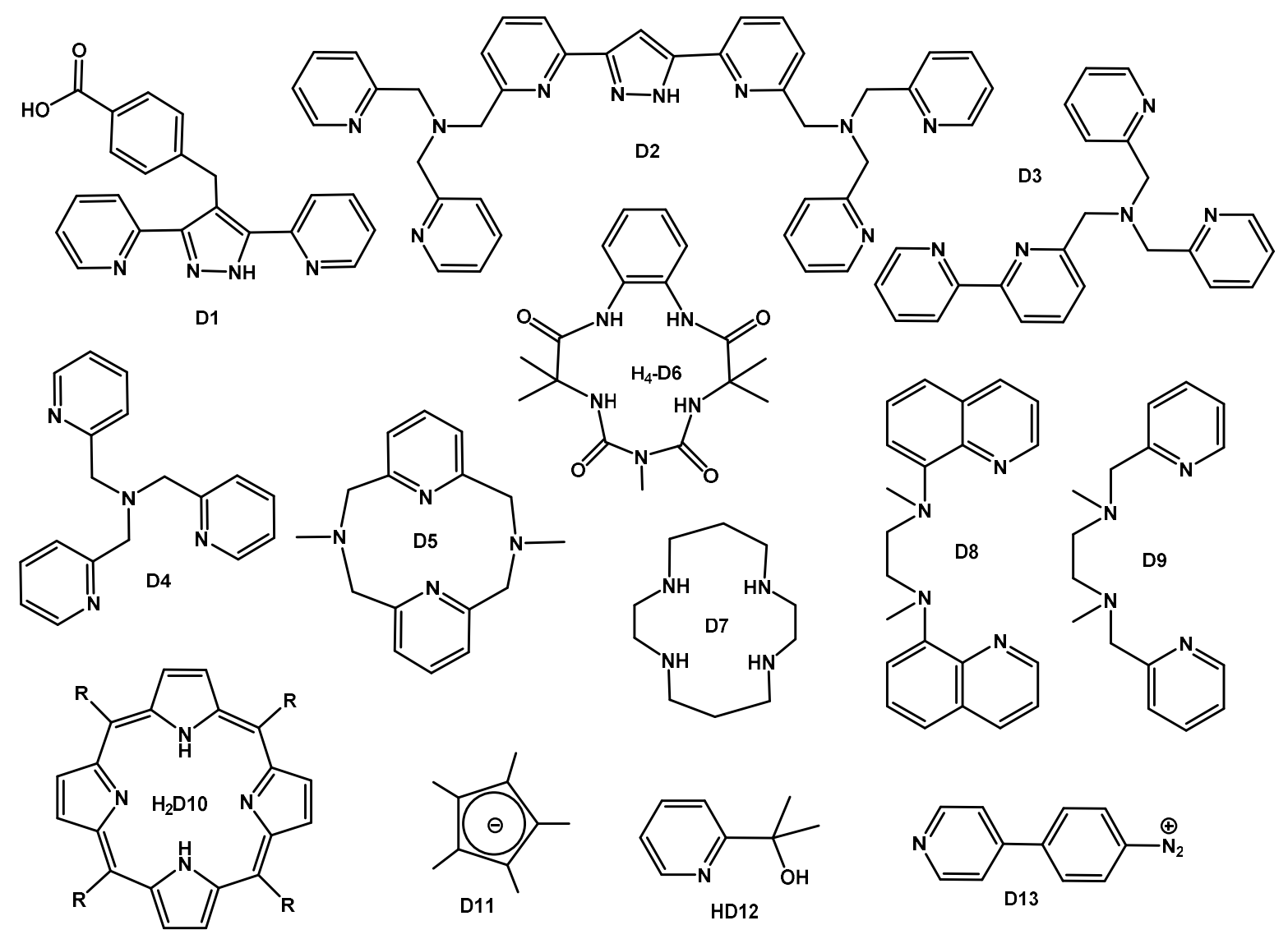




\section{REFERENCES}

${ }^{1}$ F. Berna, P. Goldberg, L. K. Horwitz, J. Brink, S. Holt, M. Bamford and M. Chazan, Proc. Natl. Acad. Sci. U.S.A., 2012, 109, E1215-E1220.

${ }^{2}$ World Energy Outlook 2016, International Energy Agency, 2016.

3 "A Milestone for Carbon Dioxide in the Atmosphere", Schwartz, J. The New York Times, 2016. www.nytimes.com/2016/10/04/science/atmospheric-carbon-dioxide-400-ppm.html

${ }^{4}$ A. Llobet and F. Meyer, Angew. Chem. Int. Ed., 2011, 50, A30-33.

${ }^{5}$ I. D. Young, M. Ibrahim, R. Chatterjee, S. Gul, F. D. Fuller, S. Koroidov, A. S. Brewster, R. Tran, R. AlonsoMori, T. Kroll, T. Michels-Clark, H. Laksmono, R. G. Sierra, C. A. Stan, R. Hussein, M. Zhang, L. Douthit, M. Kubin, C. de Lichtenberg, L. Vo Pham, H. Nilsson, M. H. Cheah, D. Shevela, C. Saracini, M. A. Bean, I. Seuffert, D. Sokaras, T.-C. Weng, E. Pastor, C. Weninger, T. Fransson, L. Lassalle, P. Brauer, P. Aller, P. T. Docker, B. Andi, A. M. Orville, J. M. Glownia, S. Nelson, M. Sikorski, D. Zhu, M. S. Hunter, T. J. Lane, A. Aquila, J. E. Koglin, J. Robinson, M. Liang, S. Boutet, A. Y. Lyubimov, M. Uervirojnangkoorn, N. W. Moriarty, D. Liebschner, P. V. Afonine, D. G. Waterman, G. Evans, P. Wernet, H. Dobbek, W. I. Weis, A. T. Brunger, P. H. Zwart, P. D. Adams, A. Zouni, J. Messinger, U. Bergmann, N. K. Sauter, J. Kern, V. K. Yachandra and J. Yano, Nature, 2016, 540, 453-457.

${ }^{6}$ A. Coehn and M. Gläser, Zeits. Anorg. Chem., 1902, 33, 9-24.

${ }^{7}$ S. W. Gersten, G. J. Samuels and T. J. Meyer, J. Am. Chem. Soc., 1982, 104, 4029.

${ }^{8}$ X. Sala, S. Maji, R. Bofill, J. Garcia-Anton, L. Escriche and A. Llobet, Acc. Chem. Res., 2014, 47, $504-516$ and references therein.

${ }^{9}$ D. R. Weinberg, C. J. Gagliardi, J. F. Hull, C. F. Murphy, C. A. Kent, B. C. Westlake, A. Paul, D. H. Ess, D. G. McCafferty and T. J. Meyer, Chem. Rev., 2012, 112, 4016-4093.

${ }^{10}$ A. Llobet, Inorg. Chim. Acta., 1994, 221, 125-131.

${ }^{11}$ E. Masllorens, M. Rodriguez, I. Romero, A. Roglans, T. Parella, J. Benet-Buchholz, M. Poyatos and A. Llobet, J. Am. Chem. Soc., 2006, 128, 5306-5307.

${ }^{12}$ A. Dovletoglou, S. A. Adeyemi and T. J. Meyer, Inorg. Chem., 1996, 35, 4120-4127.

${ }^{13}$ L. Vigara, M. Z. Ertem, N. Planas, F. Bozoglian, N. Leidel, H. Dau, M. Haumann, L. Gagliardi, C. J. Cramer and A. Llobet, Chem. Sci., 2012, 3, 2576-2586 and references therein.

${ }^{14}$ M. Murakami, D. Hong, T. Suenobu, S. Yamaguchi, T. Ogura and S. Fukuzumi, J. Am. Chem. Soc., 2011, 133, 11605-11613.

${ }^{15}$ C. J. Richmond, R. Matheu, A. Poater, L. Falivene, J. Benet-Buchholz, X. Sala, L. Cavallo and A. Llobet, Chem. Eur. J., 2014, 20, 17282-17286.

${ }^{16}$ L. Mognon, J. Benet-Buchholz and A. Llobet, Inorg. Chem., 2015, 54, 11948-11957.

${ }^{17}$ S. Roeser, P. Farras, F. Bozoglian, M. Martínez-Belmonte, J. Benet-Buchholz and A. Llobet, ChemSusChem, 2011, 4, 153-153.

${ }^{18}$ S. Romain, F. Bozoglian, X. Sala and A. Llobet, J. Am. Chem. Soc., 2009, 131, 2768-2769.

${ }^{19}$ S. Neudeck, S. Maji, I. Lopez, S. Meyer, F. Meyer and A. Llobet, J. Am. Chem. Soc., 2014, 136, 24-27.

${ }^{20}$ X. Yang and M.-H. Baik, J. Am. Chem. Soc., 2008, 130, 16231-16240.

${ }^{21}$ N. Song, J. J. Concepcion, R. A. Binstead, J. A. Rudd, A. K. Vannucci, C. J. Dares, M. K. Coggins and T. J. Meyer, Proc. Natl. Acad. Sci. U.S.A., 2015, 112, 4935-4940.

${ }^{22}$ R. Matheu, M. Z. Ertem, J. Benet-Buchholz, E. Coronado, V. S. Batista, X. Sala and A. Llobet, J. Am. Chem. Soc., 2015, 137, 10786-10795.

${ }^{23}$ S. Maji, L. Vigara, F. Cottone, F. Bozoglian, J. Benet-Buchholz and A. Llobet, Angew. Chem. Int. Ed., 2012, 51, 5967-5970.

${ }^{24}$ L. Duan, F. Bozoglian, S. Mandal, B. Stewart, T. Privalov, A. Llobet and L. Sun, Nat. Chem., 2012, 4, $418-423$.

${ }^{25}$ R. Matheu, L. Francàs, P. Chernev, M. Z. Ertem, V. Batista, M. Haumann, X. Sala and A. Llobet, ACS Catal., 2015, 5, 3422-3429.

${ }^{26}$ M. Schulze, V. Kunz, P. D. Frischmann and F. Würthner, Nat. Chem., 2016, 8, 576-583.

${ }^{27}$ See for instance papers contained in the "Forum on the Redox-Active Ligand" in Inorg. Chem. 2011,50 (20). 
${ }^{28}$ M.-K. Tsai, J. Rochford, D. E. Polyansky, T. Wada, K. Tanaka, E. Fujita and J. T. Muckerman, Inorg. Chem., 2009, 48, 4372-4383.

${ }^{29}$ P. Garrido-Barros, I. Funes-Ardoiz, S. Drouet, J. Benet-Buchholz, F. Maseras and A. Llobet, J. Am. Chem. Soc., 2015, 137, 6758-6761.

30 J. J. Concepcion, M.-K. Tsai, J. T. Muckerman and T. J. Meyer, J. Am. Chem. Soc., 2010, 132, 1545-1557. ${ }^{31}$ A. Keidel, I. López. J. Staffa, U. Kuhlmann, F. Bozoglian, C. Gimbert-Suriñach, Jordi Benet-Buchholz, P Hildebrandt and A. Llobet, ChemSusChem, 2017, 10, 551-561.

${ }^{32}$ C. Gimbert-Suriñach, D. Moonshiram, L. Francas, N. Planas, V. Bernales, F. Bozoglian, A. Guda, L. Mognon, I. López, Md A. Hoque, L. Gagliardi, C. J. Cramer and A. Llobet, J. Am. Chem. Soc. 2016, 138, 15291-15294.

${ }^{33}$ L. Mognon, S. Mandal, C. E. Castillo, J. Fortage, F. Molton, G. Aromi, Jordi Benet-Buchholz, M.-N. Collomb and A. Llobet., Chem. Sci., 2016, 7, 3304-3312.

${ }^{34}$ A. Harriman, I. J. Pickering, J. M. Thomas and P. A. Christensen, J. Chem. Soc., Faraday Trans., 1988, 84, 2795-2806.

${ }^{35}$ L. Francàs, X. Sala, J. Benet-Buchholz, L. Escriche and A. Llobet, ChemSusChem, 2009, 2, 321-329.

${ }^{36}$ A. C. Sander, A. Schober, S. Dechert and F. Meyer, Eur. J. Inorg. Chem., 2015, 4348-4353.

${ }^{37}$ B. Radaram, J. A. Ivie, W. M. Singh, R. M. Grudzient, J. H. Reibenspies, C. E. Webster and X. Zhao, Inorg. Chem., 2011, 50, 10564-10571.

${ }^{38}$ H.-Y. Wang, E. Mijangos, S. Ott and A. Thapper, Angew. Chem. Int. Ed., 2014, 53, 14499-14502.

39 J.-W. Wang, P. Sahoo and T.-B. Lu, ACS Catal., 2016, 6, 5062-5068.

${ }^{40}$ W.-T. Lee, S. B. Muñoz III, D. A. Dickie and J. M. Smith, Angew. Chem. Int. Ed., 2014, 53, 9856-9859.

${ }^{41}$ S. Pattanayak, D. R. Chowdhury, B. Garai, K. K. Singh, A. Paul, B. B. Dhar and S. S. Gupta, Chem. Eur. J., 2017, 23, 3414-3424.

42 D. Hong, S. Mandal, Y. Yamada, Y.-M. Lee, W. Nam, A. Llobet and S. Fukuzumi, Inorg. Chem., 2013, 52, 9522-9531.

${ }^{43}$ M. Zhang, M.-T. Zhang, C. Hou, Z.-F. Ke and T.-B. Lu, Angew. Chem. Int. Ed., 2014, 53, 13042-13048.

44 J. Lloret-Fillol, Z. Codola, I. Garcia-Bosch, L. Gomez, J. J. Pla and M. Costas, Nat. Chem., 2011, 3, 807-813.

${ }^{45}$ W. A. Hoffert, M. T. Mock, A. M. Appel and J. Y. Yang, Eur. J. Inorg. Chem., 2013, 3846-3857.

${ }^{46}$ G. Chen, L. Chen, S.-M. Ng, W.-L. Man and T.-C. Lau, Angew. Chem. Int. Ed., 2013, 52, 1789-1791.

${ }^{47}$ Q. Daniel, R. B. Ambre, B. Zhang, B. Philippe, H. Chen, F. Li, K. Fan, S. Ahmadi, H. Rensmo and L. Sun, ACS Catal., 2017, 7, 1143-1149.

${ }^{48}$ S. W. Sheelan, J. M. Thomsen, U. Hintermair, R. H. Crabtree, G. W. Brudvig and C. A. Schmuttenmaer, Nat. Commun., 2015, 6, 6469.

${ }^{49}$ M. W. Kanan, J. Yano, Y. Surendranath, M. Dinca, V. K. Yachandra and D. G. Nocera, J. Am. Chem. Soc., 2010, 132, 13692-13701.

${ }^{50}$ R. Sarma, A. M. Angeles-Boza, D. W. Brinkley and J. P. Roth, J. Am. Chem. Soc., 2012, 134, 15371-15386

${ }^{51}$ I. López, M. Z. Ertem, S. Maji, J. Benet-Buchholz, A. Keidel, U. Kuhlmann, P. Hildebrandt, C. J. Cramer, V. S. Batista and A. Llobet, Angew. Chem. Int. Ed., 2014, 53, 205-209.

${ }^{52}$ Catalyst performances are usually characterized in terms of turnover numbers (TONs) and turnover frequencies (TOFs). Please see any general textbook in catalysis such as "Masel, Richard I. (2001) Chemical Kinetics and Catalysis. Wiley-Interscience, New York. ISBN 0-471-24197-0". 